\title{
ASSESSMENT OF THE THERMAL BEHAVIOR OF LIGNINS FROM SOFTWOOD AND HARDWOOD SPECIES
}

\author{
Matheus Poletto ${ }^{1 *}$
}

\begin{abstract}
The thermal behavior of lignins from softwood and hardwood species has been investigated using thermogravimetry and differential scanning calorimetry. Klason Lignin from Pinus taeda and Klason lignin from Eucalyptus grandis were studied. The differential scanning calorimetry results showed that both Klason lignins studied presented similar glass transition temperature. Thermogravimetric results showed that the lignin degradation occurs in three stages. The Klason lignin of Pinus taeda is more thermally stable than Eucalyptus grandis, probably because of the higher thermal stability of the guaiacyl units in softwood lignin. The degradation of both lignins initiate by a diffusion process. However when the conversion values are higher than 0,1 the lignin degradation mechanism is a complex procedure and involves the degradation of a highly condensed aromatic structure formed at the previous degradation stages.
\end{abstract}

Keywords: Activation energy, degradation mechanism, lignin, TGA, thermal stability.

\section{INTRODUCTION}

The increased interest in the conversion of wood and its components for producing alternative fuels and chemicals necessitates a fundamental understanding of the main characteristics, composition, thermal behavior and processes involving pyrolysis of biomass (Ferdous et al. 2002, Brosse et al. 2010, Wang et al. 2015). Knowledge of the kinetics of thermal reactions is vital for predicting thermal behavior of biomass materials such as lignin ((Ferdous et al. 2002, Wang et al. 2015).

Lignin is a complex three-dimensional network natural polymer that serves as a continuous matrix component in plant cell walls (Kubo and Kadla 2005, Godoy et al. 2007, Kiaei et al. 2014). Lignin is a polyaromatic polyol that is readily available and relative inexpensive, because can be obtained from lignocellulosic wastes. Depending on the extraction method used and original source the physicalchemical characteristics differ considerably (Kubo and Kadla 2005, Wang et al. 2009). Several methods have been developed to separate lignin from the other constituents of the lignocellulosic materials (Brosse et al. 2010, Jiang et al. 2010, Wang et al. 2015). Since each separation method modifies to some degree the chemical structure of the naturally occurring lignin, so lignin is conventionally named

${ }^{1}$ Centro de Ciências Exatas, da Natureza e de Tecnologia (CENT), Universidade de Caxias do Sul (UCS), Bento Gonçalves, Rio Grande do Sul, Brazil.

•Corresponding author: mpolett1@ucs.br

Received: 28.11.2015 Accepted: 14.10.2016 
after the method of separation used. The Klason method is one of the most typical lignin determination procedures (Yasuda et al. 2001, Jiang et al. 2010). The method separates lignin as an insoluble material by depolymerization of cellulose and hemicellulose in $72 \%$ sulfuric acid followed by hydrolysis of the dissolved polysaccharides in boiling 3\% sulfuric acid (Yasuda et al. 2001).

The wood species also affects the properties of lignin (Kubo and Kadla 2005, Wang et al. 2009). Chemically, softwood lignins consist largely of guaiacylpropane units, while hardwood lignins are basically composed of both guaiacyl- and syringylpropane units (Kubo and Kadla 2005, Wang et al. 2009). Wang et al. 2009 performed pyrolysis of lignins isolated from hardwood and softwood, and found that methoxy group content has a significant influence on the pyrolysis of lignin. Bährle et al. 2014 used Klason lignin for comparing the pyrolysis behavior of hardwood and softwood lignins. They suggested that radical formation during hardwood Klason lignin pyrolysis was more frequent than that of softwood Klason lignin pyrolysis, and was mainly due to high methoxy group content in hardwood Klason lignin (Bährle et al. 2014).

Understand the pyrolysis kinetics of lignin and its correlation with physical and chemical properties of wood is important to better understand wood thermal degradation and provide useful information for rational design and scaling-up of pyrolysis reactors (Klein and Virk 2008, Jiang et al. 2010). In order to better understand the thermal degradation and pyrolysis kinetics of lignin and its correlation with their properties, this study investigates the differences in thermal behavior and degradation kinetics of two Klason lignins obtained from different tree species. The pyrolysis characteristics of Klason lignin isolated from hardwood specie (Eucalyptus grandis) and from softwood specie (Pinus taeda) were compared by thermogravimetry and differential scanning calorimetry. To better understand the pyrolysis process the lignin degradation mechanism is also evaluated.

\section{Theoretical background}

The fundamental equation used in all kinetic studies is generally described as (Bianchi et al. 2011):

$$
\frac{d \alpha}{d t}=k(T) f(\alpha)
$$

where $k$ is the rate constant and $f(\alpha)$ is the reaction model, a function dependent on the reaction mechanism. Equation (1) expresses the rate of conversion, $d \alpha / d t$, at a constant temperature as a function of the rate constant and the reduction in the reactant concentration. In this study, the conversion rate $\alpha$ is defined as:

$$
\alpha=\frac{m_{0}-m_{t}}{m_{0}-m_{f}}
$$

where $m_{0}$ is the initial weight of the sample, $m_{f}$ is the final weight and $m_{t}$ is the sample's weight at time $(t)$. The rate constant $k$ is generally given by the Arrhenius equation:

$$
k(T)=A e^{\frac{-E a}{R T}}
$$

where $E_{a}$ is the apparent activation energy $\left(\mathrm{kJ} \cdot \mathrm{mol}^{-1}\right), R$ is the gas constant $\left(8,314 \mathrm{~kJ} \cdot \mathrm{mol}^{-1} \mathrm{~K}^{-1}\right), A$ is the pre-exponential factor $\left(\mathrm{min}^{-1}\right)$ and, $T$ is the absolute temperature (K). The combination of Eqs. (1) and (3) gives the following relationship: 


$$
\frac{d \alpha}{d t}=A e^{-E_{a} / R T} f(\alpha)
$$

For a dynamic thermogravimetric analysis (TGA) in a non-isothermal experiment, introducing the heating rate $\beta=d T / d t$ into Equation (4), Equation (5) is obtained as:

$$
\frac{d \alpha}{d T}=\left(\frac{A}{\beta}\right) e^{-E_{a} / R T} f(\alpha)
$$

Equations (4) and (5) are the fundamental expressions of analytical methods used to calculate kinetic parameters on the basis of the TGA data ( Poletto et al. 2010, Sanchez-Silva et al. 2012).

\section{Flynn-Wall-Ozawa method}

The activation energy values for the degradation process were determined by the isoconversional Flynn-Wall-Ozawa (FWO) method. This method can be used for determination of the $E_{a}$ values without any knowledge of the reaction mechanisms. This is defined by Equation (6) (Flynn and Wall 1966, Ozawa 1965):

$$
\log \beta=\log \left[\frac{A E_{a}}{g(\alpha) R}\right]-2,315-0,4567 \frac{E_{a}}{R T}
$$

where $\beta$ is the heating rate, $A$ is the pre-exponential factor, $g(\alpha)$ is a function of the conversion, $E_{a}$ is the activation energy and $\mathrm{R}$ is the gas constant. Therefore, for different heating rates $(\beta)$ and a given degree of conversion $(\alpha)$, a linear relationship is observed by plotting $\log \beta$ vs. $1 / T$, and the $E_{a}$ is obtained from the slope of the straight line (Flynn and Wall 1966, Ozawa 1965).

\section{Criado method}

The degradation reaction mechanism can be determined using the Criado method (Criado et al. 1989 ), which can accurately determine the reaction mechanism in a solid reaction process. This is defined by a $Z(\alpha)$ type function:

$$
Z(\alpha)=\frac{(d \alpha / d t)}{\beta} \pi(x) T
$$

where $x=E_{d} / R T$ and $\pi(x)$ is an approximation of the temperature integral that cannot be expressed in a simple analytical form. In this study, were used the fourth rational expression of Senum and Yang (Pérez-Maqueda and Criado 2000), which gives errors lower than $10^{-5} \%$ when $\mathrm{x}>20$. The master curves as a function of the conversion degree corresponding to the different models listed in Table 1 (Bianchi et al. 2011) were obtained according to equation (8): 


$$
Z(\alpha)=f(\alpha) g(\alpha)
$$

From equations (5) and (8), the following relationship can be derived:

$$
Z(\alpha)=\frac{d \alpha}{d T} \frac{E_{a}}{R} e^{\frac{E_{a}}{R T}} P(x)
$$

Equation (8) is used to plot the $\mathrm{Z}(\alpha)$ versus $\alpha$ curves for the different models listed in Table 1, whereas Equation (9) is used to represent the experimental curve. By comparing these two curves, the type of mechanism involved in the thermal degradation can be identified. The activation energy values obtained using FWO method were used to determine the degradation mechanisms proposed by Criado (Criado et al. 1989). This method uses references theoretical curves obtained from Eq. (8) that are derivatives of $f(\alpha)$ and $g(\alpha)$ functions represented in Table 1, called master curves, which are compared with experimental data for determination of the mechanism of a solid-state reaction process.

Table 1. Algebraic expressions for $g(\alpha)$ and $f(\alpha)$ for the most frequently used mechanisms of

\begin{tabular}{|c|c|c|}
\hline Mechanism - Solid state process & $g(\alpha)$ & $f(\alpha)$ \\
\hline $\mathrm{A}_{2}$ - Nucleation and growth (Avrami eq.1) & {$[-\ln (1-\alpha)]^{1 / 2}$} & $2(1-\alpha)[-\ln (1-\alpha)]^{3}$ \\
\hline $\mathrm{A}_{3}$ - Nucleation and growth (Avrami eq.2) & {$[-\ln (1-\alpha)]^{1 / 3}$} & $3(1-\alpha)[-\ln (1-\alpha)]^{3 / /}$ \\
\hline $\mathrm{A}_{4}$ - Nucleation and growth (Avrami eq.3) & {$[-\ln (1-\alpha)]^{1 / 4}$} & $4(1-\alpha)[-\ln (1-\alpha)]^{\pi / \alpha}$ \\
\hline $\begin{array}{l}\mathrm{R}_{1} \text { - Phase boundary controlled reaction (one- } \\
\text { dimensional movement) }\end{array}$ & $\alpha$ & 1 \\
\hline $\begin{array}{l}R_{2} \text { - Phase boundary controlled reaction (contracting } \\
\text { area) }\end{array}$ & {$\left[1-(1-\alpha)^{1 / 2}\right]$} & $2(1-\alpha)^{1 / 2}$ \\
\hline $\begin{array}{l}R_{3}-\text { Phase boundary controlled reaction (contracting } \\
\text { volume) }\end{array}$ & {$\left[1-(1-\alpha)^{1 / 3}\right]$} & $3(1-\alpha)^{2 / 4}$ \\
\hline $\mathrm{D}_{1}$ - One-dimensional diffusion & $\alpha^{2}$ & $(1 / 2) \alpha$ \\
\hline $\begin{array}{l}D_{2} \text { - Two-dimensional diffusion (Valensi equation) } \\
D_{3} \text { - Three-dimensional diffusion (Jander equation) }\end{array}$ & $\begin{array}{c}(1-\alpha) \ln (1-\alpha)+\alpha \\
{\left[1-(1-\alpha)^{1 / 3}\right]^{2}}\end{array}$ & $\begin{array}{c}-[\ln (1-\alpha)]^{-1} \\
(3 / 2)\left[1-(1-\alpha)^{K / 2}\right]^{-1}(1-\alpha)^{3 / 4}\end{array}$ \\
\hline $\begin{array}{l}\mathrm{D}_{4} \text { - Three-dimensional diffusion (Ginstling- } \\
\text { Brounshtein equation) }\end{array}$ & {$[1-(2 / 3) \alpha]-(1-\alpha)^{3 / 2}$} & $(3 / 2)\left[1-(1-\alpha)^{x}\right]^{-1}$ \\
\hline $\begin{array}{l}F_{1} \text { - Random nucleation with one nucleus on the } \\
\text { individual particle }\end{array}$ & $-\ln (1-\alpha)$ & $1-\alpha$ \\
\hline $\begin{array}{l}\mathrm{F}_{2} \text { - Random nucleation with two nuclei on the } \\
\text { individual particle }\end{array}$ & $1 /(1-\alpha)$ & $(1-\alpha)^{2}$ \\
\hline $\begin{array}{l}\mathrm{F}_{3} \text { - Random nucleation with three nuclei on the } \\
\text { individual particle }\end{array}$ & $1 /(1-\alpha)^{2}$ & $(1 / 2)(1-\alpha)^{3}$ \\
\hline
\end{tabular}
solid state processes (Criado et al. 1989).

\section{Materials}

The lignin samples used in this study were obtained from wood wastes of the lumber industry in Brazil. Klason lignin from softwood Pinus taeda and Klason lignin from hardwood Eucalyptus grandis were prepared as follows. First the extractives were eliminated from wood via Soxhlet extraction in triplicate using ethanol/benzene; ethanol; and hot water, as solvents, in accordance with the Tappi T204 cm-97 standard. 
Afterwards the Klason lignin was obtained in accordance with the Tappi T222om-02 standard. The lignin purification procedure occurs after extensively washed the samples with deionized water until obtain a filtrate with $\mathrm{pH}$ equal to 7 . The samples were dried in vacuum oven at $105^{\circ} \mathrm{C}$ for $4 \mathrm{~h}$ before the thermal analysis.

\section{Thermogravimetric analysis (TGA)}

The thermogravimetric analysis (TGA50 - Shimadzu) was carried out under $\mathrm{N}_{2}$ atmosphere with a purge gas flow of $50 \mathrm{~cm}^{3} \cdot \mathrm{min}^{-1}$ from 25 to $800^{\circ} \mathrm{C}$. Approximately $10 \mathrm{mg}$ of each sample was used. The heating rate of $30^{\circ} \mathrm{C} \cdot \mathrm{min}^{-1}$ was used for comparison the thermogravimetric behavior of the lignins studied. To calculate the kinetics parameters the TGA was carried out at four different heating rates (5, 10, 20 and $\left.40^{\circ} \mathrm{C} \cdot \mathrm{min}^{-1}\right)$.

\section{Differential scanning calorimetry (DSC)}

Differential scanning calorimetry was used for determination the $\mathrm{T}_{\mathrm{g}}$ values of lignin. The analysis was performed using a DSC50 - Shimadzu under $\mathrm{N}_{2}$ atmosphere with a purge gas flow of $50 \mathrm{~cm}^{3} \cdot \mathrm{min}^{-1}$. The heating rate of $30^{\circ} \mathrm{C} \cdot \mathrm{min}^{-1}$ was used over the temperature range of -50 to $200^{\circ} \mathrm{C}$. The measurements were made using $5 \mathrm{mg}$ of each sample. The glass transition temperature $\left(\mathrm{T}_{\mathrm{g}}\right)$ was recorded as the midpoint of the heat capacity transition.

\section{RESULTS AND DISCUSSIONS}

\section{Thermal behaviour}

\section{Differential scanning calorimetry}

The DSC analysis of the LPIT and LEUG shows that the glass transition temperature $\left(\mathrm{T}_{\mathrm{g}}\right)$ is similar for the two samples studied (Figure 1). LEUG showed a slight higher $\mathrm{T}_{\mathrm{g}}$ value, $\mathrm{T}_{\mathrm{g}}=161^{\circ} \mathrm{C}$ than LPIT, $\mathrm{T}_{\mathrm{g}}=158^{\circ} \mathrm{C}$. Generally, $\mathrm{T}_{\mathrm{g}}$ in lignin lies between 100 and $180^{\circ} \mathrm{C}$, which is high when compared to the $\mathrm{T}_{\mathrm{g}}$ values of most synthetic polymers (Feldman et al. 2001). The high $\mathrm{T}_{\mathrm{g}}$ is in large part associated with the formation of hydrogen bonding between the phenolic hydroxyl groups in the lignin main chain (Buranov et al. 2010). The higher quantities of aromatic rings in the lignin main chain also contribute to the high $\mathrm{T}_{\mathrm{g}}$ (Buranov et al. 2010).

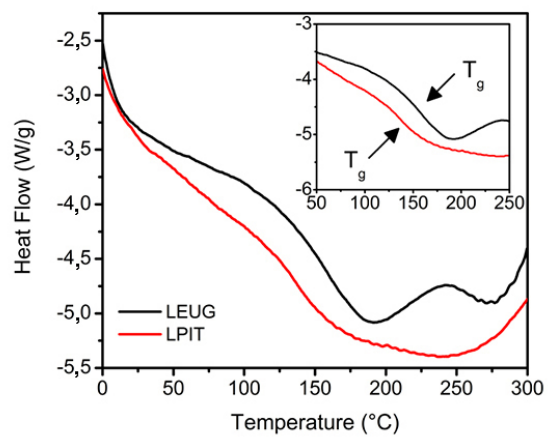

Figure 1. Glass transition temperature $\left(\mathrm{T}_{\mathrm{g}}\right)$ of the lignins studied determined by DSC.

The $\mathrm{T}_{\mathrm{g}}$ values for lignin obtained using Klason method in this work are higher than others values reported in the literature. Kubo and Kadla (2005) studying commercially kraft lignin from hardwood and softwood obtained $\mathrm{T}_{\mathrm{g}}$ values of $93^{\circ} \mathrm{C}$ and $119^{\circ} \mathrm{C}$, respectively. Tejado et al. (2007) found $\mathrm{T}_{\mathrm{g}}$ values of $100^{\circ} \mathrm{C}$ and $144^{\circ} \mathrm{C}$ for lignins from organosolv and kraft isolation methods. The higher $\mathrm{T}_{\mathrm{g}}$ from $\mathrm{K}_{\mathrm{g}}^{\mathrm{g}} \mathrm{kson}$ 
lignin is probably due to its higher condensed structure (Klein and Virk 2008, Jiang et al. 2010) when compared with lignin obtained from others separation methods.

\section{Thermogravimetric analysis}

Figure 2 shows the TGA and DTG curves of the lignins studied. As shown in the thermogravimetric curve, the thermal degradation of both lignins proceeded over a wide temperature range from approximately $180^{\circ} \mathrm{C}$ to $800^{\circ} \mathrm{C}$.

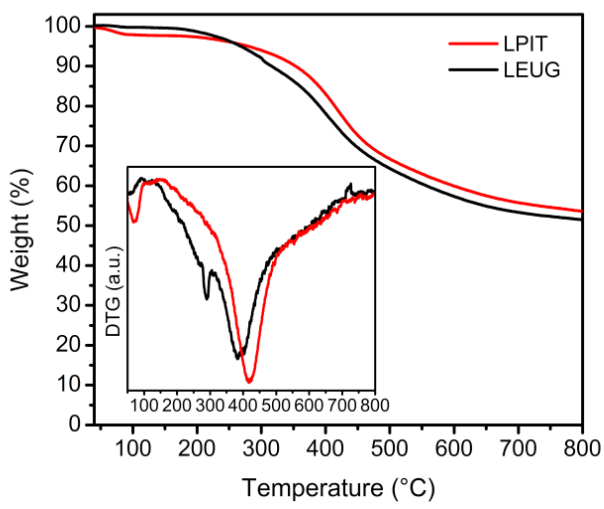

Figure 2. TGA and DTG curves for lignins at heating rate of $30^{\circ} \mathrm{C} \cdot \mathrm{min}^{-1}$.

The lignin degradation occurs in three stages. In the first degradation stage between $30-100^{\circ} \mathrm{C}$ the weight loss was less than $2 \%$ and can be mainly attributed to the loss of moisture (Poletto and Zattera 2013) present in the samples. After the first weight loss, the degradation process is slower between $110-170^{\circ} \mathrm{C}$ and a plateau can be seen in this temperature range for both samples. The mainly degradation process for both lignins starts at around $180^{\circ} \mathrm{C}$. As shown in Figure 2, after $200^{\circ} \mathrm{C}$ the LPIT thermal stability was higher than that of LEUG. The initial weight loss temperature (Ti) considered as the temperature at which the sample loses $5 \%$ of its weight is $49^{\circ} \mathrm{C}$ higher in LPIT than in LEUG, as presented in Table 2 .

Table 2. Initial weight loss temperature, DTG peak and \% residue for the lignins studied.

\begin{tabular}{|c|c|c|c|}
\hline Lignin samples & $\begin{array}{c}\mathrm{T}_{\mathrm{i}}\left({ }^{\circ} \mathrm{C}\right) \\
5 \mathrm{wt} \% \text { loss }\end{array}$ & $\begin{array}{c}\text { DTG peak } \\
\left({ }^{\circ} \mathrm{C}\right)\end{array}$ & $\begin{array}{c}\text { Residue at } 800^{\circ} \mathrm{C} \\
(\%)\end{array}$ \\
\hline LPIT & 306 & 438 & 53,6 \\
LEUG & 268 & 389 & 51,5 \\
\hline
\end{tabular}

It is in the second stage, between $180-500^{\circ} \mathrm{C}$, which the main lignin degradation process occurs. For LEUG a small peak can be observed at around $300^{\circ} \mathrm{C}$, which could be associated with some residual hemicellulose content. The DTG peak occurs at $389^{\circ} \mathrm{C}$ for LEUG, while for LPIT the peak is centered at $438^{\circ} \mathrm{C}$. Both curves present a broad peak, which is associated with the primary lignin pyrolysis (Jiang et al. 2010). Pyrolytic degradation in this region involves fragmentation of inter-unit linkages, releasing monomeric phenols into the vapor phase (Tejado et al. 2007), that may accelerate the degradation process. The LPIT sample has a higher thermal stability than LEUG. The differences in the structure of lignins and chemical natures of lignin from different tree species could account for the diversities of their thermal degradation behaviors (Wang et al. 2009). The syringyl and guaiacyl 
units are built into the lignin macromolecule mainly by ether bonds, and the ether bonds between syringyl units are easier to scission than those between guaiacyl units (Wang et al. 2009, Frankenstein and Schmitt 2006). So, this result in higher thermal stability of softwood lignin (LPIT), mainly formed by guaiacyl units, when compared with hardwood lignin (LEUG), composed by guaiacyl and syringyl units, which may explain the highest thermal stability of LPIT sample.

Above $500^{\circ} \mathrm{C}$ the degradation process is possibly related to the slow decomposition of some aromatic rings in lignin (Tejado et al. 2007, Zhao et al. 2010). At $800^{\circ} \mathrm{C}$ more than $50 \%$ of all lignin samples still remain unvolatilized due to the formation of highly condensed aromatic structures (Tejado et al. 2007).

\section{Degradation kinetics}

The plots of the FWO method, which was used for the determination of the activation energy values for both lignins studied, show a general trend. Because the kinetic behavior is similar for both lignins, only LEUG was chosen as a representative model for the presentation of the activation energy results. Therefore, Figure 3 shows the results of the application of the FWO method with $\alpha$ values from 0,1 to 0,9 . The activation energy values were calculated from the angular coefficient obtained from the straight line fit, according to Eq. 6 .

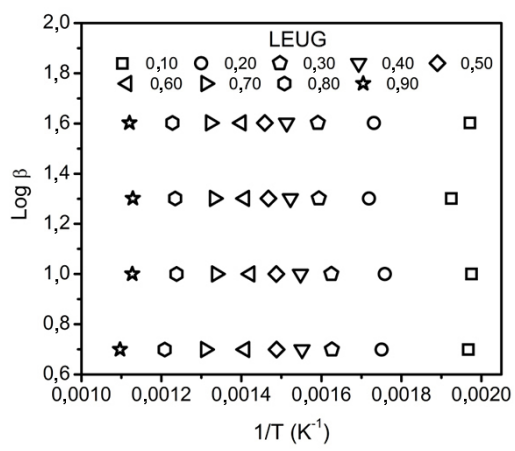

Figure 3. Data obtained from plot $\log \beta v s .1 / T\left(\mathrm{~K}^{-1}\right)$ using FWO method for LEUG.

The activation energy $(E)$, linear correlation coefficient $(R)$, and frequency factor $(A)$ in relation to conversion values $(\alpha)$ for both lignins studied are presented in Table 3. It can be observed that LEUG present higher $\mathrm{E}_{\mathrm{a}}$ values than LPIT. This behavior may be associated with the higher volatility during pyrolysis of LEÜG, which could be verified when compared the frequency factor. The frequency factor is a reflection of the frequency of the collisions between the reacting molecules (Jiang et al. 2010). The frequency factor for LEUG is higher than LPIT, which might indicate that the number of collisions between the free radicals formed during the LEUG lignin degradation is much more intense in this sample leading to an increase in $\mathrm{E}_{\mathrm{a}}$ values (Ferdous et al. 2002). 
Table 3. Activation energies and frequency factor obtained using the FWO method.

\begin{tabular}{|l|c|c|c|c|c|c|}
\hline & \multicolumn{3}{|c|}{ LEUG } & \multicolumn{3}{c|}{ LPIT } \\
\hline $\boldsymbol{\alpha}$ & $\left.\mathbf{E}_{\mathbf{a}} \mathbf{( k J . m o l}^{-1}\right)$ & $\mathbf{R}$ & $\mathbf{A}$ & $\left.\mathbf{E}_{\mathbf{a}} \mathbf{( k J . m o l}^{-1}\right)$ & $\mathbf{R}$ & $\mathbf{A}$ \\
\hline 0,1 & 77,0 & $-0,942$ & $6,53 \times 10^{4}$ & 29,7 & $-0,954$ & $3,05 \times 10^{4}$ \\
0,2 & 245,7 & $-0,981$ & $1,55 \times 10^{20}$ & 99,2 & $-0,964$ & $2,16 \times 10^{6}$ \\
\hline 0,3 & 271,9 & $-0,985$ & $1,27 \times 10^{21}$ & 153,5 & $-0,988$ & $3,15 \times 10^{10}$ \\
0,4 & 297,3 & $-0,983$ & $2,46 \times 10^{22}$ & 182,7 & $-0,995$ & $3,84 \times 10^{12}$ \\
0,5 & 343,8 & $-0,987$ & $2,47 \times 10^{25}$ & 221,1 & $-0,989$ & $2,06 \times 10^{15}$ \\
0,6 & 483,4 & $-0,993$ & $1,34 \times 10^{35}$ & 309,6 & $-0,988$ & $3,47 \times 10^{21}$ \\
\hline 0,7 & 689,3 & $-0,987$ & $1,26 \times 10^{48}$ & 546,5 & $-0,986$ & $2,37 \times 10^{37}$ \\
\hline 0,8 & 1031,5 & $-0,986$ & $4,12 \times 10^{67}$ & 1223,9 & $-0,980$ & $2,42 \times 10^{79}$ \\
0,9 & 1537,0 & $-0,979$ & $5,10 \times 10^{92}$ & 1041,7 & $-0,995$ & $1,66 \times 10^{61}$ \\
\hline
\end{tabular}

The evaluation of conversion values also reveals a different behavior for lignins studied. For LEUG when $\alpha$ is equal to 0,1 only the loss of moisture occurs, because the lower value of $\mathrm{E}_{\mathrm{a}}$. For LPIT the degradation rate is slower than in LEUG and the loss of moisture occurs between conversion values range of $0,1-0,2$. For LEUG the main lignin degradation occurs between $0,2-0,6$ while for LPIT the main lignin degradation occurs between $0,3-0,6$. In this stage several degradation reactions occur, involved different $\mathrm{E}_{\mathrm{a}}$ values. According to Faravelli et al. (2010) the first relevant radical initiation reaction in lignin involves the scission of $\mathrm{C}-\mathrm{O}$ bond in the $\beta-\mathrm{O}-4$ lignin structure forming phenoxy radicals. A bond energy of about 242,8 kJ.mol ${ }^{-1}$, as proposed by Back (1989), allows the activation energy for this reaction in the gas phase. However, $\mathrm{E}_{\mathrm{a}}$ values between $176-188 \mathrm{~kJ}^{\mathrm{mol}}{ }^{-1}$ can also be obtained (Jiang et al. 2010). For LEUG the $\mathrm{E}_{\mathrm{a}}$ values are very close to the maximum value $\left(242,8 \mathrm{~kJ} \cdot \mathrm{mol}^{-1}\right)$ when for LPIT between $0,3-0,4$ the $\mathrm{E}_{\mathrm{a}}$ values are more close to the minimum range values. The scission of phenylether compounds present in lignin generally involves activation energy values at around $300 \mathrm{~kJ}$.mol ${ }^{-1}$ (Klein and Virk 2008). For LEUG this step occurs between 0,4-0,5 however for LPIT this step only occurs at conversion value equal to 0,6 probably because the slower conversion rate in this sample, which may be associated with the higher thermal stability of the guaiacyl units. When the conversion values are between $0,6-0,7$ the degradation process initiate a different pathway. In this stage the degradation of the highly condensed aromatic structures formed takes place in both lignins and both $\mathrm{E}_{\mathrm{a}}$ values and frequency factor are very different from the previous stages. Additionally, the conversion range between 0,7-0,9 may be associated with degradation occurring in a narrow and accelerated range of degradation and another degradation mechanism could be occurs at higher conversion values (Yao et al. 2008, Ornaghi Jr et al. 2014).

The $E_{a}$ values obtained using the FWO method were used to determine the thermal degradation mechanisms proposed by Criado et al. (1989). This method uses reference theoretical curves obtained from Equation (8) that are derivatives of the $f(\alpha)$ and $g(\alpha)$ functions represented in Table 1; called master curves, they are compared to experimental data to determine the mechanism of the solid-state degradation process (Criado et al. 1989). 
As can be seen in Table 1, the algebraic expressions that represent the theoretical mechanisms are separated into four groups: $A_{n}, R_{n}, D_{n}$ and $F_{n}$. Respectively, these mechanisms describe: nuclei formation processes for the propagation of thermal degradation; diffusion processes that are related to the heat transfer capacity along the material structure; reaction mechanisms controlled by the surface of the sample; and the random degradation of nuclei. The determination of the $Z(\alpha)$ values was carried out using a heating rate $(\beta)$ of $10^{\circ} \mathrm{C} \cdot \mathrm{min}^{-1}$, and the calculated $\mathrm{Z}(\alpha)$ values were determined by applying the $E_{a}$ values obtained with the FWO method to Equation (9).

Figure 4 presents the master curves as well as the results of the experimental data obtained. For better comparison, only the $\mathrm{D}_{\mathrm{n}}$ and $\mathrm{F}_{\mathrm{n}}$ theoretical mechanism are presented in Figure 4, because the $A_{n}$ and $\mathrm{R}_{\mathrm{n}}$ theoretical mechanism not fit the experimental data.

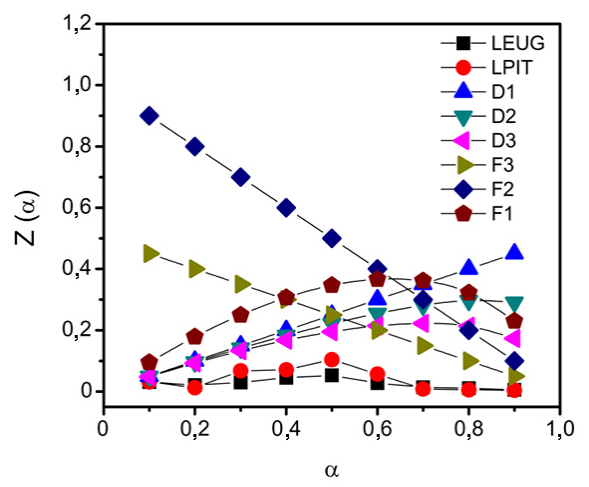

Figure 4. Master curves and experimental data obtained using the Criado method for lignins studied.

It can be seen from Figure 4 that for both lignin samples when $\alpha=0,1$ the experimental value overlap the D1, D2 and D3 curves. According to literature, these degradation mechanisms refer to a diffusion process in one, two and three dimensions, respectively (Criado et al. 1989). The degradation process initiate by a diffusion process, however when the conversion values are in the range of $\alpha=0,2-$ 0,6 the experimental values did not overlap any theoretical curve. The experimental values are more closely related with a D3 mechanism and the shape of the experimental curve is also similar to a D3 mechanism in this $\alpha$ interval, but the experimental values did not overlap the D3 theoretical curve. This result indicate that in the range of $\alpha=0,2-0,6$ the lignin degradation process did not follow any degradation mechanism related to Criado method. When the conversion values are in the range of 0,7-0,9 the shape of the experimental curve for both lignins studied present a different trend. The experimental points are furthest from the theoretical values indicating a different thermal degradation behavior at this interval. As discussed earlier, in this stage the degradation of the highly condensed aromatic structures formed during the previous stages takes place leading to slow decomposition reactions of these aromatic compounds. 


\section{CONCLUSIONS}

The DSC results showed that both Klason lignins studied independent of the wood specie presented similar glass transition temperature. Thermogravimetric results showed that LPIT is more thermally stable than LEUG, because of the higher thermal stability of the guaiacyl units in softwood lignin. The degradation kinetics reveals that lignin from hardwood presented higher activation energy and frequency factor values than softwood lignin. The degradation of both lignins initiate by a diffusion process, however when the conversion values are higher than 0,1 the results showed that the lignin degradation mechanism is a complex procedure and involves the degradation of a highly condensed aromatic structure.

\section{ACKNOWLEDGEMENTS}

The author thank Cambará S/A and Madeireira Gold Martini that supplying wood samples used for obtained the lignins studied.

\section{REFERENCES}

Back, M.H. 1989. Comment on the thermal decomposition of anisole and the heat of formation of the phenoxy radical. Journal of Physical Chemistry 93:6880-6881.

Bährle, C.; Custodis, V.; Jeschke, G.; van Bokhoven, J.; Vogel, F. 2014. In situ observation of radicals and molecular products during lignin pyrolysis. ChemSusChem 7:2022-2029.

Bianchi, O.; Martins, J. De N.; Fiorio, R.; Oliveira, R.V.B.; Canto, L.B. 2011. Changes in activation energy and kinetic mechanism during EVA crosslinking. Polymer Testing 30:616-624.

Brosse, N.; El Hage, R.; Chaouch, M.; Pétrissans, M.; Dumarçay, S. 2010. Investigation of the chemical modifications of beech wood lignin during heat treatment. Polymer Degradation and Stability 95:1721-1726.

Buranov, A.U.; Ross, K.A.; Mazza, G. 2010. Isolation and characterization of lignins extracted from flax shives using pressurized aqueous ethanol. Bioresource Technology 101:7446-7455.

Criado, J.M.; Málek, J.; Ortega, A. 1989. Applicability of the master plots in kinetic analysis of non-isothermal data. Thermochimica Acta 147:377-385.

Faravelli, T.; Frassoldati, A.; Migliavacca, G.; Ranzi, E. 2010. Detailed kinetic modeling of the thermal degradation of lignins. Biomass and Bioenergy 34:290-301.

Feldman, D.; Banu, D.; Campanelli, J.; Zhu, H. 2001. Blends of vinylic copolymer with plasticized lignin: thermal and mechanical properties. Journal of Applied Polymer Science 81:861-874.

Ferdous, D.; Dalai, A.K.; Bej, S.K.; Thring, R.W. 2002. Pyrolysis of lignins: experimental and kinetics studies. Energy \& Fuels 16:1405-1412. 
Flynn, J.H.; Wall, L.A. 1966. General treatment of the thermogravimetry of polymers. Journal of Research of the National Bureau of Standards 70A:487-523.

Frankenstein, C.; Schmitt, U. 2006. Microscopic studies on modified wall structure and lignin topochemistry in xylem fibres of poplar after wounding. Maderas-Cienc Tecnol 8(2):93-106.

Godoy, E.A.; Rodrigues, J.C.C.; Alves, A.M.M.; Lazo, D.A. 2007. Content and quality study of the lignin by analytical pyrolysis in Pinus caribaea. Maderas-Cienc Tecnol 9(2):179-188.

Jiang, G.; Nowakowski, D. J.; Bridgwater, A.V. 2010. A systematic study of the kinetics of lignin pyrolysis. Thermochimica Acta 498:61-66.

Kiaei, M.; Kord, B.; Vaysi, R. 2014. Influence of residual lignin content on physical and mechanical properties of kraft pulp/PP composites. Maderas-Cienc Tecnol 16(4):495-503.

Klein, M.T.; Virk, P.S. 2008. Modeling of lignin thermolysis. Energy \& Fuels 22:2175-2182.

Kubo, S.; Kadla, J. 2005. Hydrogen bonding in lignin: a Fourier transform infrared model compound study. Biomacromolecules 6:2815-2821.

Ornaghi Jr., Poletto, M.; Zattera, A.J., Amico, S.C. 2014. Correlation of the thermal stability and the decomposition kinetics of six different vegetal fibers. Cellulose 21: 177-188.

Ozawa T. 1965. A new method of analyzing thermogravimetric data. Bulletin of the Chemical Society of Japan 38:1881-1886.

Pérez-Maqueda, L.A.; Criado, J.M. 2000. The accuracy of Senum and Yang's approximations to the Arrhenius integral. Journal of Thermal Analytical and Calorimetry 60:909-915.

Poletto, M.; Dettenborn, J.; Pistor, V.; Zeni, M.; Zattera, A.J. 2010. Materials Produced from Plant Biomass. Part I: Evaluation of Thermal Stability and Pyrolysis of Wood. Materials Research 13:375-379.

Poletto, M.; Zattera, A.J. 2013. Materials Produced from Plant Biomass. Part III: degradation kinetics and hydrogen bonding in lignin. Materials Research 16:1065-1070.

Sanchez-Silva, L.; López-González, D.; Villaseñor, J.; Sánchez, P.; Valverde, J.L. 2012. Thermogravimetric-mass spectrometric analysis of lignocellulosic and marine biomass pyrolysis. Bioresource Technology 109:163-172.

Tejado, A.; Peña, C.; Labidi, J.; Echeverria, J.M.; Mondragon, I. 2007. Physico-chemical characterization of lignins from different sources for use in phenol-formaldehyde resin synthesis. Bioresource Technology 98:1655-1663.

Yao, F.; Wu, Q.; Lei, Y.; Guo, W.; Xu, Y. 2008. Thermal decomposition kinetics of natural fibers: activation energy with dynamic thermogravimetric analysis. Polymer Degradation and Stability 93:9098.

Yasuda, S.; Fukushima, K.; Kakehi, A. 2001. Formation and chemical structures of acid-soluble lignin I: sulfuric acid treatment time and acid-soluble lignin content in hardwood. Journal of Wood Science 47:69-72.

Wang, S.; Wang, K.; Liu, Q.; Gu, Y.; Luo, Z.; Cen, K.; Fransson, T. 2009. Comparison of the pyrolysis behavior of lignins from different tree species. Biotechnology Advances 27:562-567. 
Wang, S.; Ru, B.; Lin, H.; Sun, W.; Luo, Z. 2015. Pyrolysis behaviors of four lignin polymers isolated from the same pine wood. Bioresource Technology 182:120-127.

Zhao, X.; Liu, D. 2010. Chemical and thermal characteristics of lignins isolated from Siam weed stem by acetic acid and formic acid delignification. Industrial Crops and Products 32:284-291. 